\title{
Adult Standardized Concentration of Chemotherapy Intravenous Infusion: New Initiative in Saudi Arabia
}

\author{
Yousef Ahmed Alomi* ${ }^{*}$, BSC \\ Pharm, MSc. Clin Pharm, BCPS, BCNSP, DiBA, \\ CDE, Critical Care Clinical Pharmacists, TPN \\ Clinical Pharmacist, Freelancer Business Plan- \\ ner, Content Editor and Data Analyst, Riyadh, \\ Saudi Arabia.
}

Faiz Abdullah. Bahadig, R.Ph,

Informatics Pharmacist, Pharmaceutical Care Department, King Abdul-Aziz Medical, City-WR-Jeddah, Ministry of National Guard, Saudi Arabia.

Hani Alhamdan, BSc.Pharm, MSc. Pharm, MBA, Director, Pharmaceutical Care services Department at KAMC-Jeddah, Ministry of National Guard, Saudi Arabia.

\section{Correspondence:}

Dr. Yousef Ahmed Alomi, Bsc. Pharm, msc. Clin pharm, bcps, bCNSP, DiBA, CDE Critical Care Clinical Pharmacists, TPN Clinical Pharmacist, Freelancer Business Planner, Content Editor and Data Analyst, P.O.BOX 100 Riyadh 11392, Riyadh, SAUDI ARABIA.

Phone no: +966 504417712

E-mail:yalomi@gmail.com
Received: 18-09-2019;

Accepted: 30-11-2019

Copyright: () the author(s), publisher and licensee International Journal of Pharmacology and Clinical Sciences. This is an open-access article distributed under the terms of the Creative Commons Attribution Non-Commercial License, which permits unrestricted non-commercial use, distribution, and reproduction in any medium, provided the original work is properly cited.

This is an open access article distributed under the terms of the Creative Commons AttributionNonCommercial-ShareAlike 4.0 License

Access this article online

\begin{tabular}{|c|c|}
\hline & www.ijpcs.net \\
\hline & DOI: \\
\hline$\square$ & \\
\hline
\end{tabular}

\begin{abstract}
Objectives: To explore the adult standardized concentration of chemotherapy agent intravenous infusion as new initiatives in the Kingdom of Saudi Arabia. Methods: It is a new initiative project drove by national standardized concentration of chemotherapy agent services. The projects formulated from the international business model, pharmacy project guidelines and project management institution guidelines of a new project. The initiative project is written through project management professionals and contained of several parts, including the initial phase, the planning phase, the execution phase, the monitoring and controlling phase. Results: The adult standardized concentration of chemotherapy medications intravenous infusion services with a defined vision, mission and goals. The services had various benefits including clinical and economic on patients as explored in the review. The continuous of the project assured by risk management model description. In addition, the monitoring and controlling of the services as declared. The transition to operation project though closing project stage explored in the analysis. Conclusion: The adult standardized concentration of chemotherapy agent intravenous infusion services is a new initiative part of the intravenous admixture program. The standardized concentration of chemotherapy medications will reduce medication misadventures, decrease healthcare professional workload and avoid economic burden on healthcare system; it is highly recommended to implement in the Kingdom of Saudi Arabia.
\end{abstract}

Keywords: Adult, Standardized, Concentration, Chemotherapy, Medications, Intravenous, Saudi Arabia.

\section{INTRODUCTION}

The national medication safety program implemented several years back. ${ }^{[1]}$ The program consisted of multiple elements that are counting but not limited to medication safety assessment, the clinical outcome of medications safety and economic outcomes of medications safely. ${ }^{[1]}$ The medication's safety covered all medications with an emphasis on high alert medications with adults and patients' populations. The biohazard medications or chemotherapy therapy one of the high alert medications. ${ }^{[2]}$ The United States of Pharmacopeia released safety handling of cytotoxic medications and the American Society of Heath system Pharmacist repeated they released the guidelines prevention of chemotherapy medication errors. ${ }^{[3,4]}$ Several factors were distressing the preparation of oncology medications to commit errors that are including but not limited to the following; a few workforces of pharmacy staff, high workload load and not unified guidelines of chemotherapy preparation. ${ }^{[3,4]}$ The American Society of Health-System Pharmacists (ASHP) stated initiatives about standardized concentration to prevent medication errors for all medications but not included chemotherapy. [5,6] Several publications had been done about the standardized concentration of medication except chemotherapy and the outcome of the standardized concentration services. ${ }^{[7-12]}$ The author, based on the best of their knowledge was not familiar with any initiative project of standardized concentration of chemotherapy. The aim of the study is to review the standardized concentration of chemotherapy medications in the Kingdom of Saudi Arabia.

\section{Method of the Project}

It is a new initiative project drove from the national IV admixture and chemotherapy program. ${ }^{[13]}$ The task force team of standardized chemotherapeutic concentration formulated and contained of from the author's expert in the parenteral medications. The committee focused and drove the pharmacy parenteral administration guidelines and from the textbook and international litterateur Standardized concentration of chemotherapeutic written by utilizing the international business model, pharmacy project guidelines project management institution guidelines of a new project. ${ }^{[14-17]}$ The standardized concentration familiar based on the acceptable concentration, daily dose and the volume of bag as possible. The project is written through project management professionals and contained of several parts, including the initial phase, the planning phase, the execution phase and the monitoring and controlling phase. 


\section{Initiative Phase}

\section{Assessment Needs}

Every day the pharmacist and pharmacy technician prepare several parenteral medications with different concentrations and multiplediluentsolutions. Besides, variousdoses for adults, patients and neonatal for different indicators. At the same time, the physician writes various intravenous prescriptions with different doses and concentrations. Also, the nurses administer multiple medications with different concentrations and solutions to various patients.

All those factors might lead to an increase in workload for healthcare professionals and pharmacy staff and succeeding medication errors in prescribing or preparation or dispensing and administration. The standardized one to two concentrations with the specific solution will decrease the workload and medication errors at all stages of medication management.

\section{SWOT Analysis}

There is a new analysis of popular tools called the SWOT Analysis, which means the strengths, weaknesses and opportunities elements. The strengths points of the project are medication safety prevention elements, healthcare providers and pharmacy workload reductions. On the other hand, the weak points are limited elements number of diluent solution and medication concentration. Also, the opportunity points are the quality patient safety program implementation and elements of the accreditation procedures. Besides, the threat points are if the administration banner which is not obtainable and if the pharmacy strategic plan which does not happen.

\section{Market Analysis}

The intravenous admixture services found onethird of the Ministry of Health hospitals based on the last survey, while all non-MOH hospitals and some private hospitals had IV admixture services. All they had adult parenteral preparation manual. It contained medications, role of administration, range of concentration and maximum concentration. However, there is no fixed or standardized concentration for each preparation. Even if it happened, it would not cover all medications. The adult's total parenteral nutrition had been standardized. The cardiopulmonary resuscitation medication or electrolyte in the processes to standardized in the nearest future.
Planning Phase

\section{Scope of the Project}

The project covers all parenteral, intravenous chemotherapy with standardized fixed concentration with regular and maximum one. That is based on update therapeutic adults doing and frequently over 24 per each cycle. It is including the type of solution dissolve or reconstitution inside it.

\section{Vision, Missions, Goals}

The vision of the project is best adults' standardized concentration and stability of intravenous chemotherapy, while the message is to deliver adults a standardized concentration of intravenous chemotherapy with most stabilized solution. The aim of the project is to standardize the adult's concentration of chemotherapy, to prevent mistakes of adult concentration of chemotherapy, to decrease the workload chemotherapy preparation and to avoid any needless wastage cost of intravenous chemotherapy.

\section{Project Description}

The following policies were put in place for every pharmacist and other health care individuals: ${ }^{[18,19]}$

$\checkmark$ The adult standardized concentration of chemotherapy committee should be formulated at healthcare organizations.

$\checkmark$ The adult standardized concentration of chemotherapy committee should consist of oncology IV pharmacist and pharmacy technician, adult's oncology nursing representative and adult oncology surgical or medical representative and oncology pediatrics physician and nurse representative.

$\checkmark$ The committee revises the Adult standardized concentration of chemotherapy and updates at least annually.

$\checkmark$ The education and training sessions should be conducted by the committee to all healthcare providers, including physicians and nurses, with pharmacy staff.

$\checkmark$ The adult standardized concentration of chemotherapy distributed to healthcare sectors at the institutions.

$\checkmark$ The physician writes the prescription based on the adult standardized concentration of chemotherapy.

$\checkmark$ If the physician wishes to prescribe outside the adult standardized concentration of chemotherapy guidelines, he should document the justification.

$\checkmark$ The prescription should send to the pharmacy and oncology IV pharmacist and pharmacy technician will prepare it based on the standardized concentration of medications.

$\checkmark$ The pharmacy staff sends the medications to the oncology nursing department and the nurse administers the medications based on the adult standardized concentration of chemotherapy guidelines.

$\checkmark$ The pharmacy department should measure the clinical outcome of the adult standardized concentration of chemotherapy

$\checkmark$ The pharmacy department should measure the economic outcome of the adult standardized concentration of chemotherapy

$\checkmark \quad$ The pharmacy department should document any prescription non-adherence to adult standardized concentration of chemotherapy

\section{Plan Cost Management}

Each new project, the management team should recognize the financial budget, which comprises the cost of educational courses, the cost of the management team meeting and the cost of updated references. The budget shod be observed throughout the project.

\section{Executing Phase}

\section{Management Team}

The project should establish by task force contained of oncology clinical pharmacist, oncology distributive pharmacist, oncology pharmacy technician, pharmacy total quality management, medical oncology physician and surgical oncology physician. The team should implement the follow the project. The clinical and economical in the healthcare system should be determined with regular update apprising of adult's standardized parental oncology medications. The team should appeal from pharmaceutical companies to replace oncology preparation by the readymade fixed concentration of chemotherapy and supportive therapy.

\section{Education and Training}

The new project wants education and training for pharmacy staff, including pharmacists and pharmacy technicians, about the project, preparation and dispensing of medications. Besides, education and training for healthcare providers, including physicians and nurses, about the project and prescribing and administration of medications, respectively. The team management member should have an orientation about the project and any 


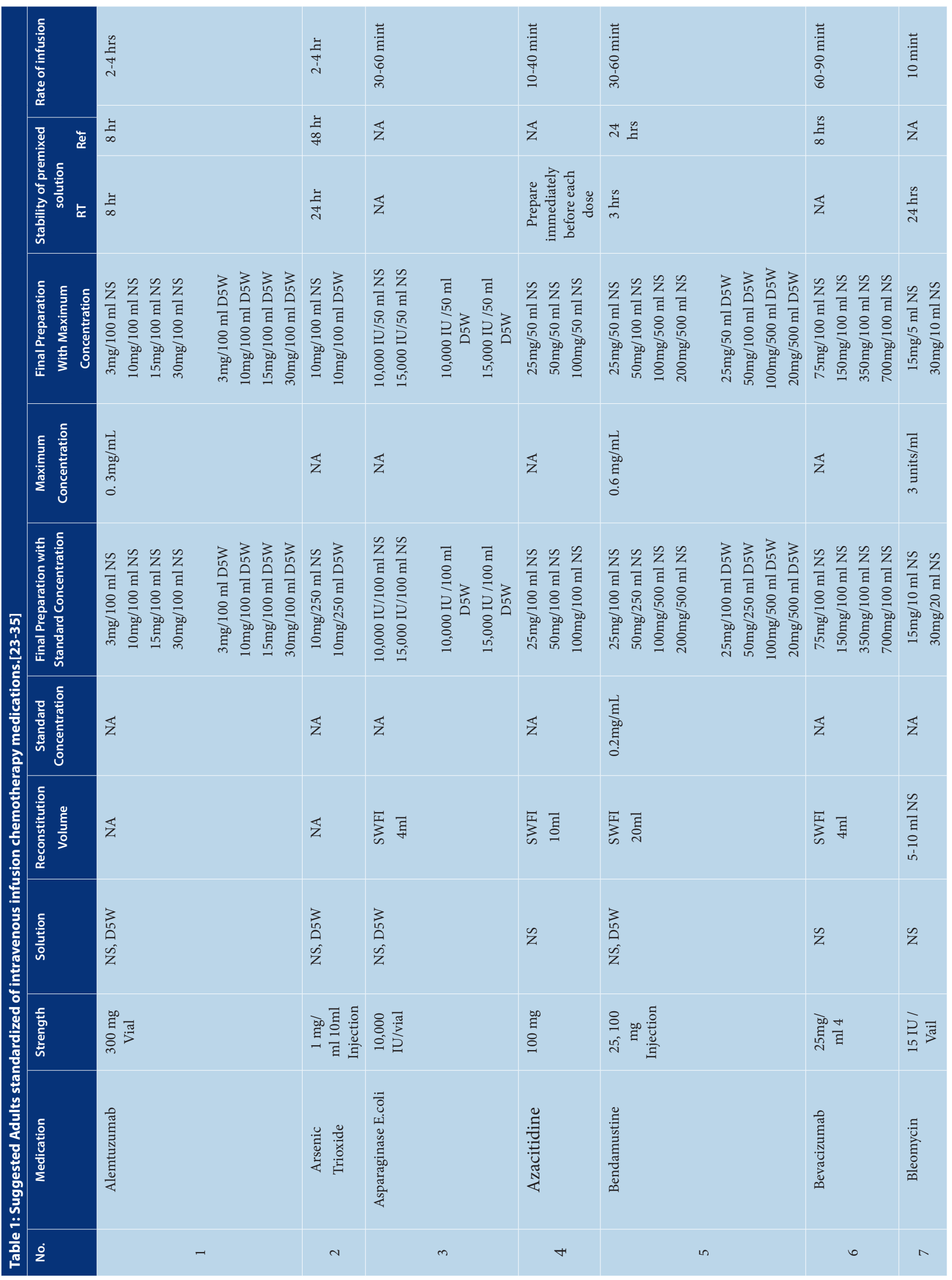




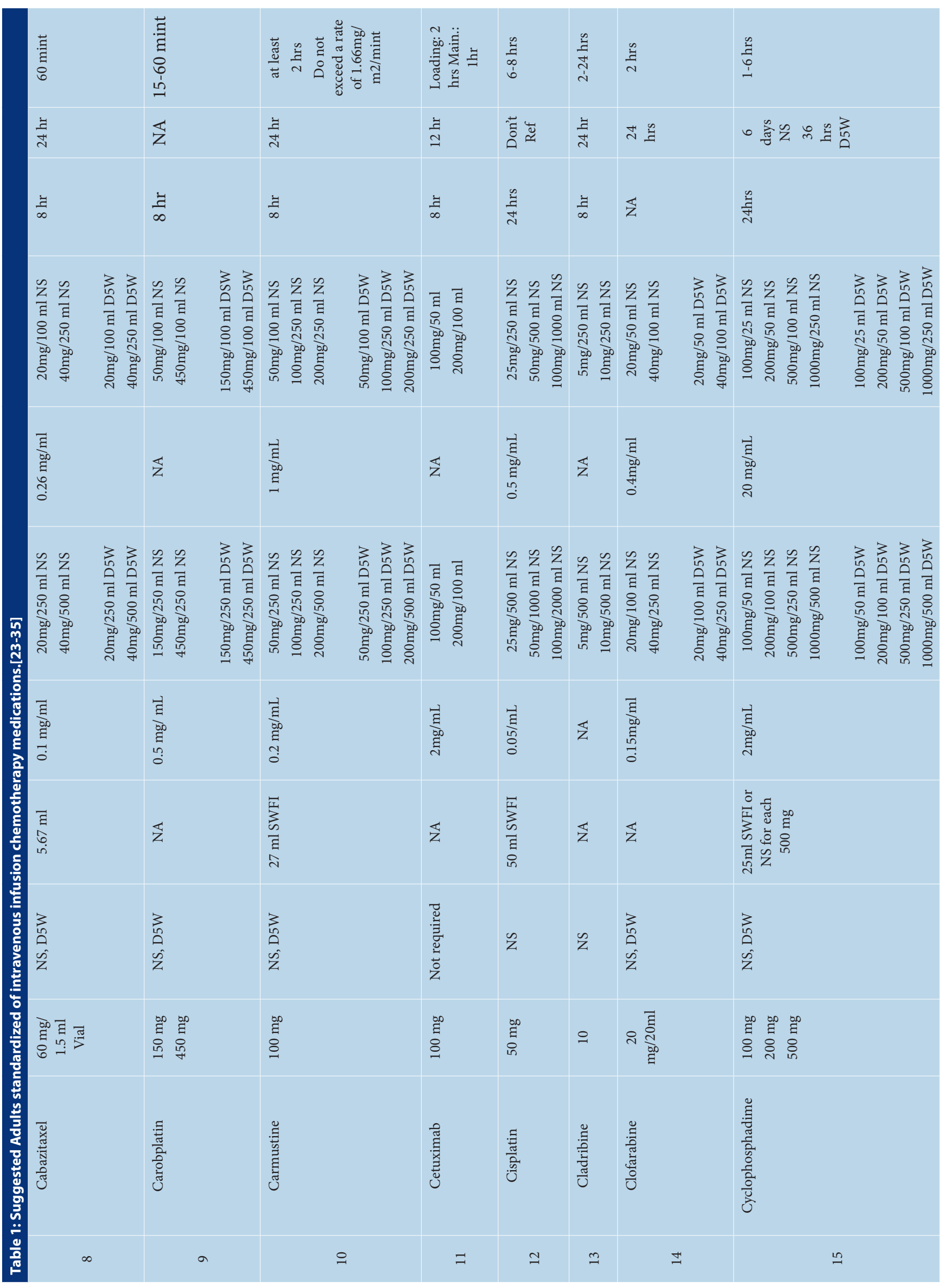




\begin{tabular}{|c|c|c|c|c|c|c|c|c|c|}
\hline 参 & & 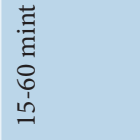 & & $\begin{array}{l}\text { 表 } \\
0 \\
0 \\
0 \\
\end{array}$ & & $\begin{array}{l}\vec{\Xi} \\
\text { 音 } \\
8\end{array}$ & $\begin{array}{l}\text { 节 } \\
\text { हू }\end{array}$ & 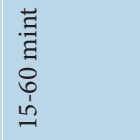 & \\
\hline$\overleftrightarrow{z}$ & & $\stackrel{\sim}{ٌ} \cong$ & & $\stackrel{\infty}{a} \cong$ & & $\stackrel{\infty}{+} \cong$ & $\stackrel{\sim}{\sim} \cong$ & $\overleftrightarrow{z}$ & \\
\hline$\overbrace{\substack{\mathrm{C} \\
-\infty}}^{\infty}$ & & $\frac{\mathscr{m}}{\infty}$ & & 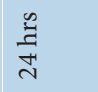 & & $\frac{\mathscr{2}}{3}$ & $\overleftrightarrow{z}$ & $\overleftrightarrow{z}$ & \\
\hline 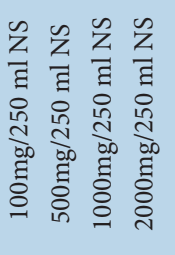 & 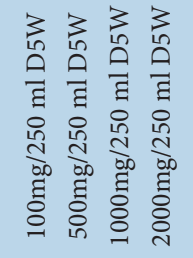 & 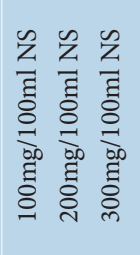 & 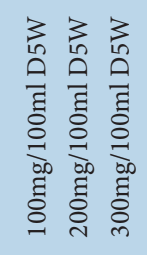 & 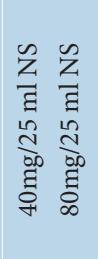 & 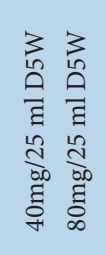 & 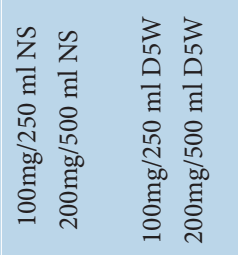 & 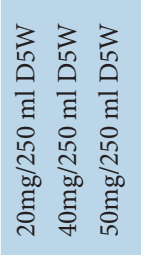 & 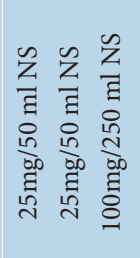 & 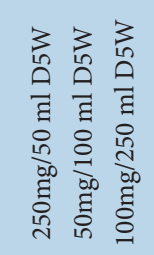 \\
\hline$\overleftrightarrow{z}$ & & $\overleftrightarrow{z}$ & & $\overleftrightarrow{z}$ & & $\begin{array}{l}\vec{z} \\
\frac{\Xi}{00} \\
\vdots \\
\vdots \\
0 \\
0\end{array}$ & $\overleftrightarrow{z}$ & $\overleftrightarrow{z}$ & \\
\hline 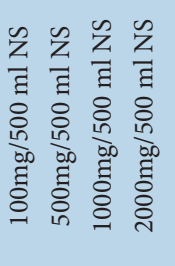 & 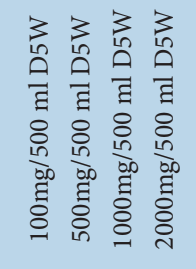 & 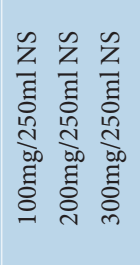 & 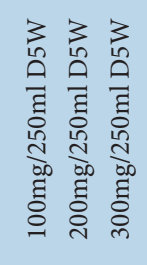 & 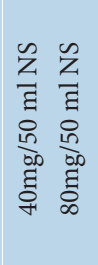 & 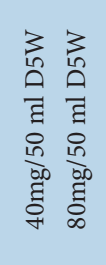 & 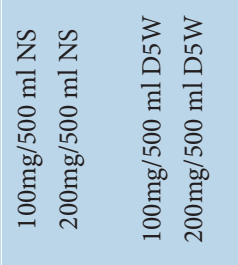 & 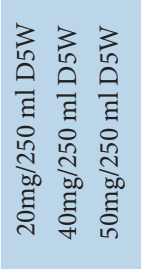 & 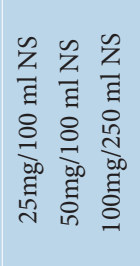 & 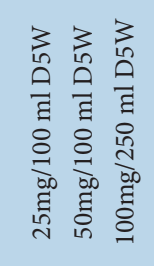 \\
\hline$\overleftrightarrow{z}$ & & $\overleftrightarrow{z}$ & & $\overleftrightarrow{z}$ & & $\begin{array}{l}\overrightarrow{\mathrm{E}} \\
\text { है } \\
\text { है } \\
0\end{array}$ & $\overleftrightarrow{z}$ & $\overleftrightarrow{z}$ & \\
\hline$\overleftrightarrow{z}$ & & $\begin{array}{l}\bar{\Xi} \\
\text { ă } \\
\text { aे }\end{array}$ & & 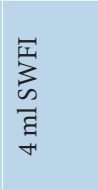 & & $\overleftrightarrow{z}$ & $\overleftrightarrow{z}$ & 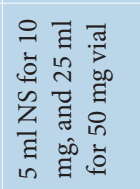 & \\
\hline 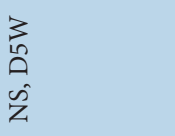 & & $\begin{array}{l}3 \\
\text { ch } \\
\text { ch } \\
\text { ż }\end{array}$ & & $\begin{array}{l}3 \\
\text { n } \\
\text { n } \\
\text { ñ }\end{array}$ & & $\begin{array}{l}3 \\
\text { in } \\
\text { vin } \\
z\end{array}$ & $\begin{array}{l}3 \\
4 \\
0\end{array}$ & $\begin{array}{l}3 \\
\text { un } \\
0 \\
\text { s } \\
z\end{array}$ & \\
\hline 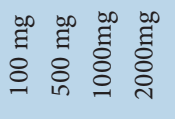 & & 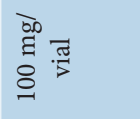 & & 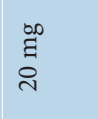 & & 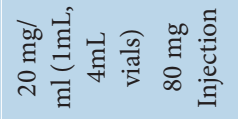 & 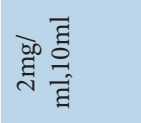 & 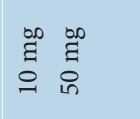 & \\
\hline 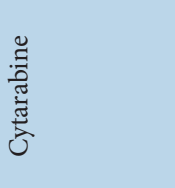 & & 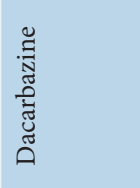 & & 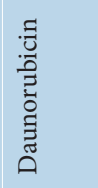 & & 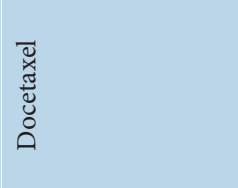 & 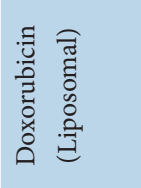 & 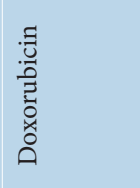 & \\
\hline & ְ & & 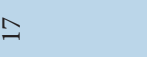 & & $\infty$ & 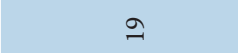 & त) & & $\vec{\sim}$ \\
\hline
\end{tabular}




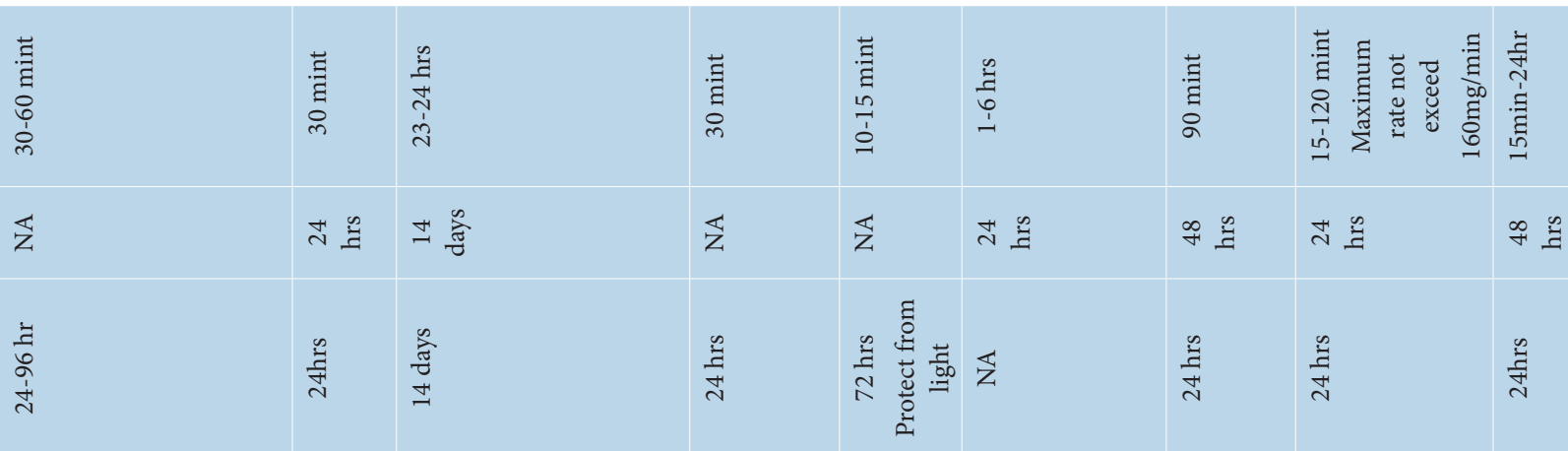

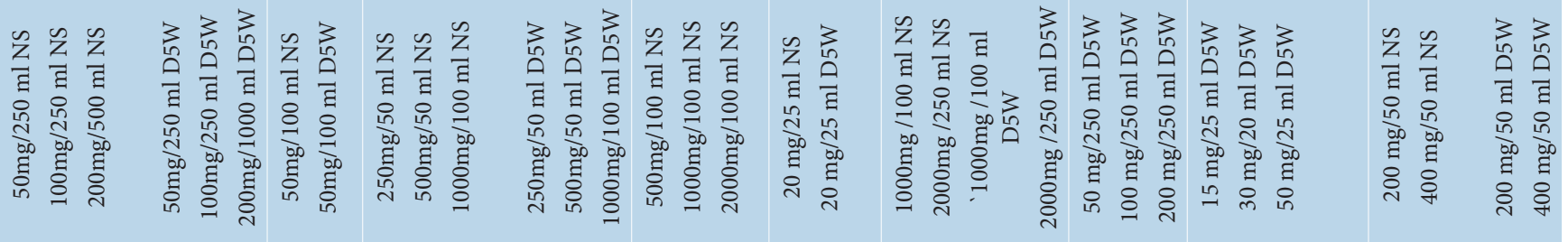

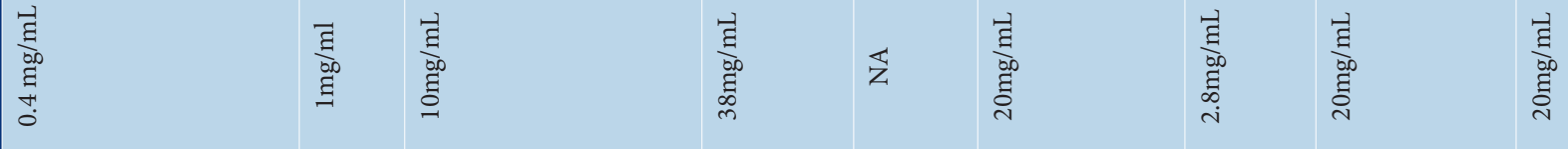

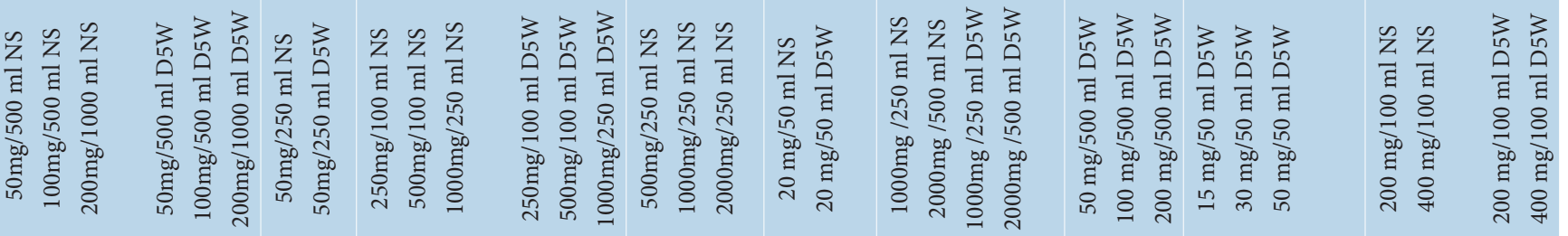

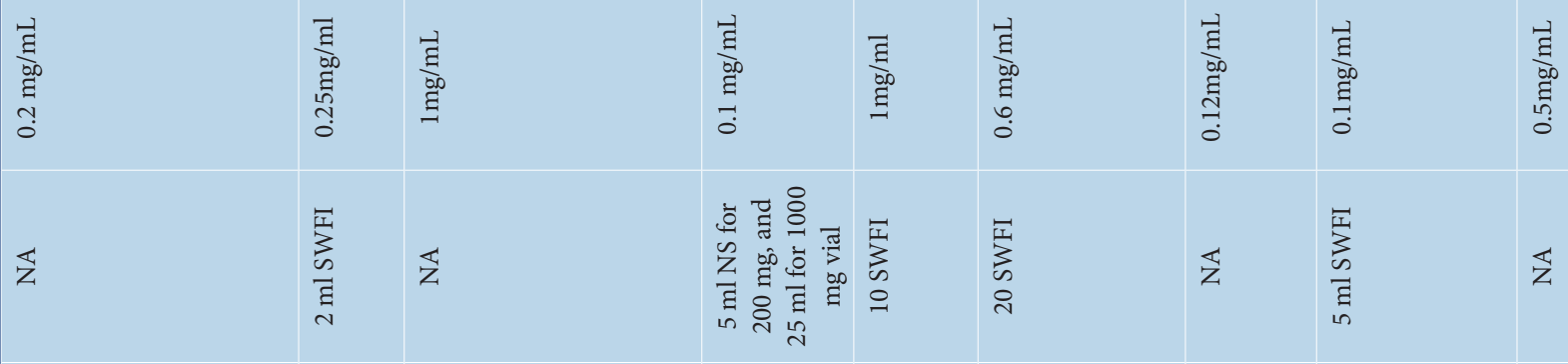

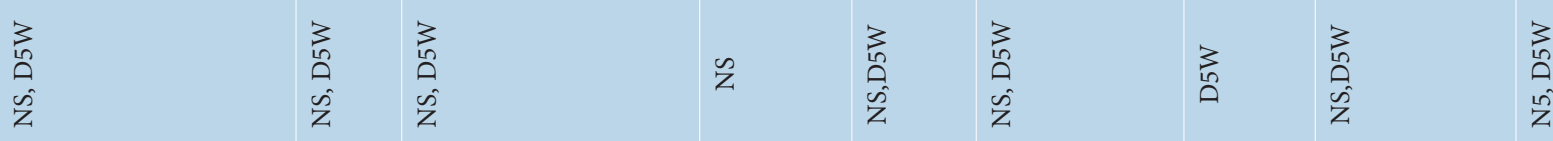

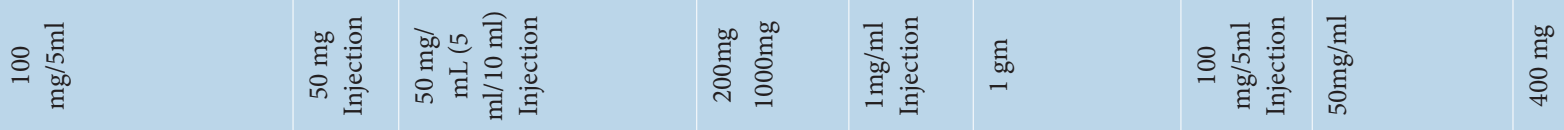

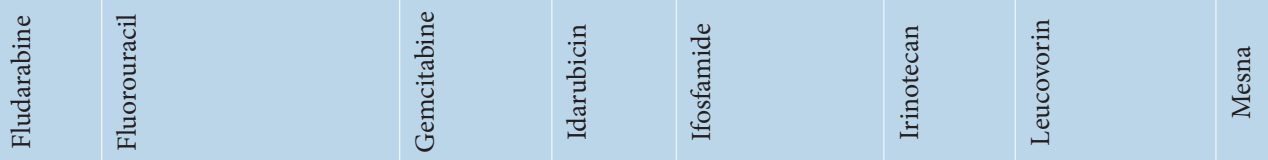

ส

$\stackrel{\sim}{\sim}$

กิ

ข้

ลิ

$\stackrel{\infty}{\sim}$

ขิ 


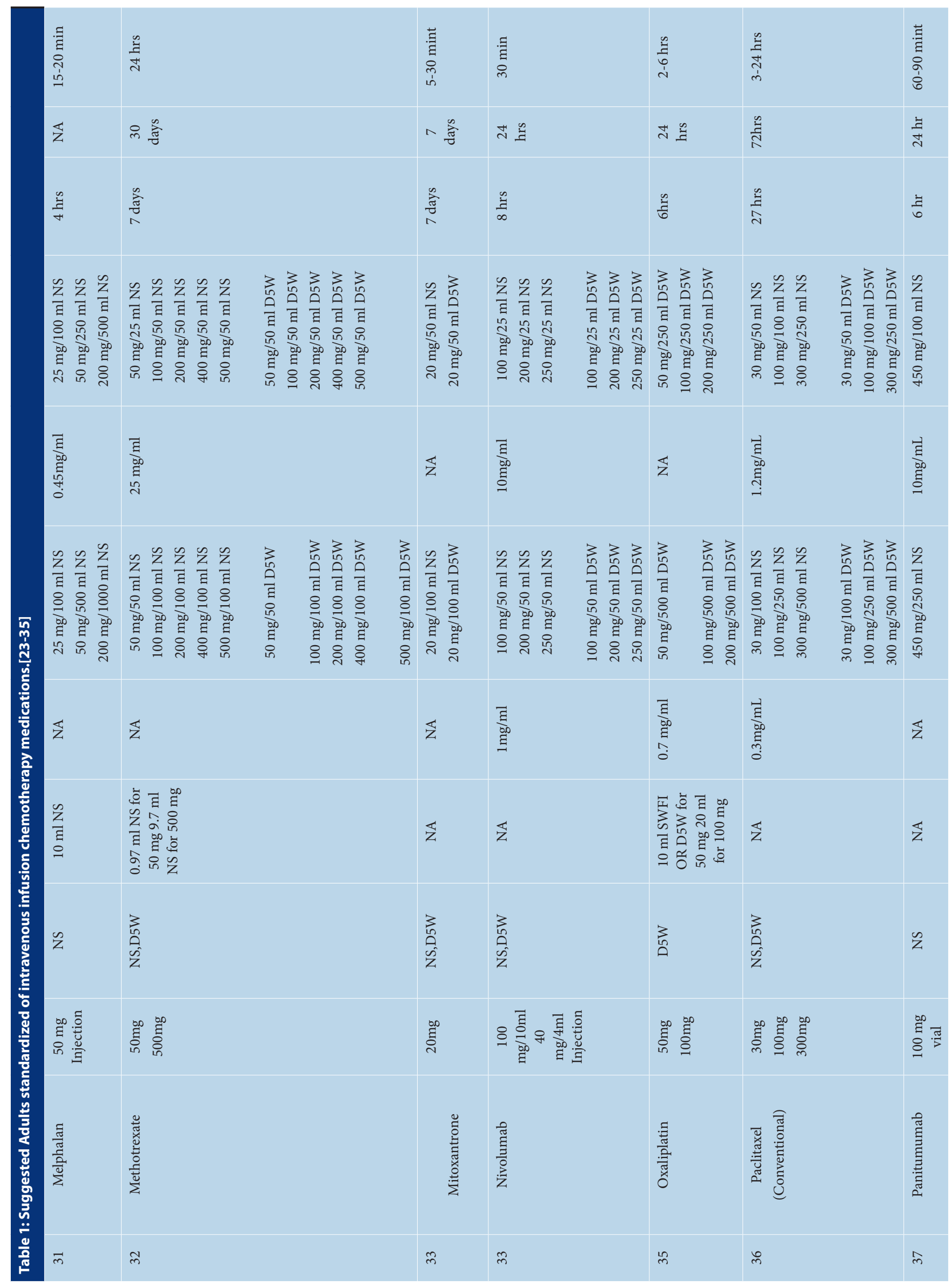




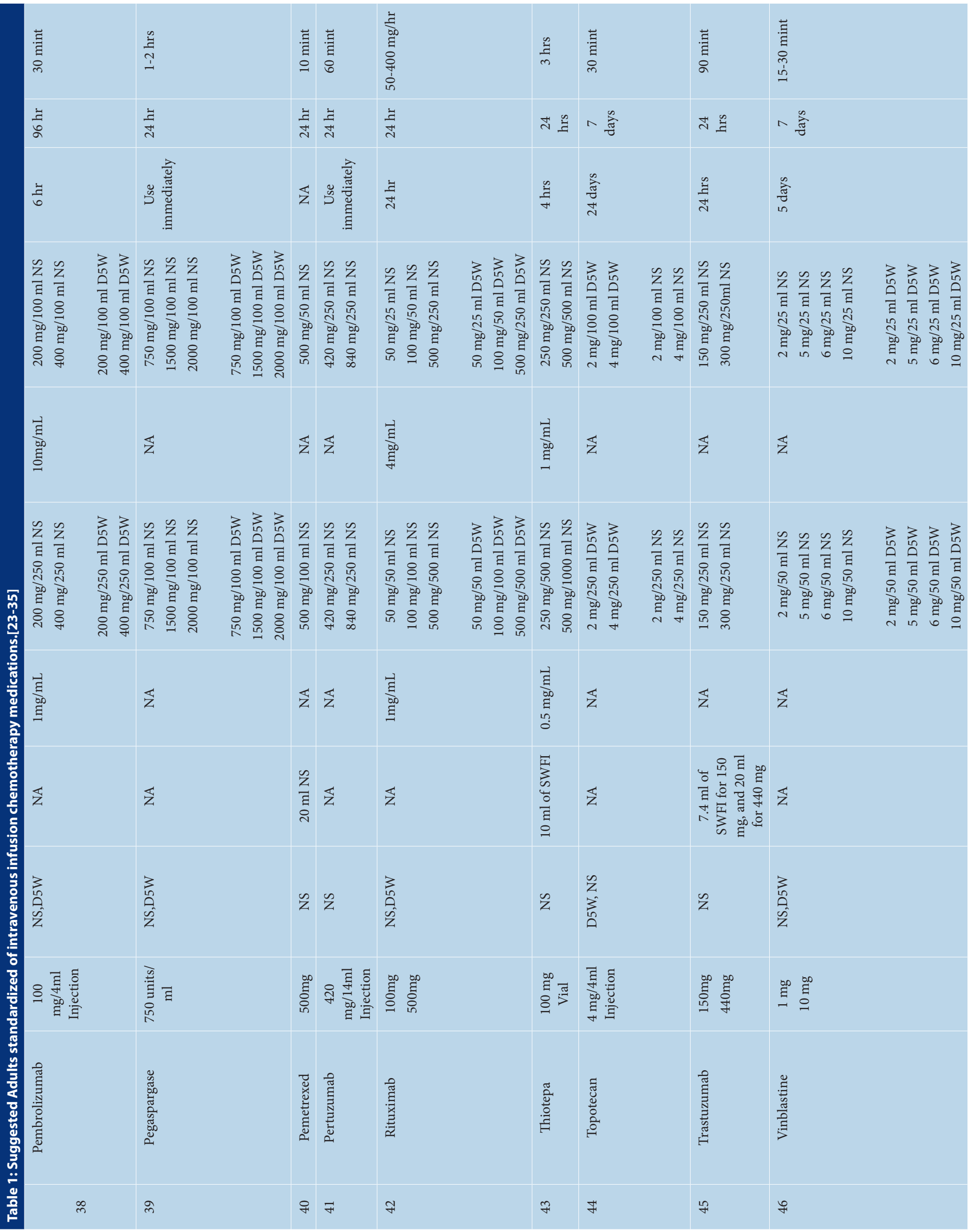




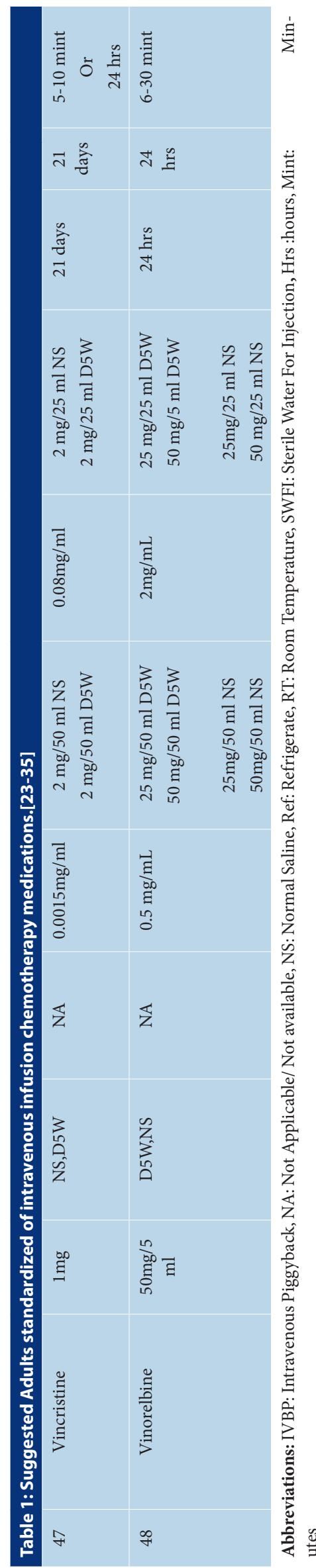

new pharmacy or healthcare staff join the institutions.

\section{Monitoring and Controlling Phase Project \\ Total Quality Management}

The total quantity management during new project adults' standardized concentration of chemotherapy medications is one the vigorous tool to monitor the implementation and the project impact assessment. There are several total quality tools used with the current project and the balance scored cards was one of them. The tools monitor four-part that's including the customer, finance, internal process, education and innovation. ${ }^{[20]}$ An example of internal processes was the assessment of healthcare services of adult's standardized concentration of chemotherapy medications. In the education and innovation types, the procedures of clinical outcome of adults standardized concentration of chemotherapy medications, which could reflect the education and capability of pharmacists and pharmacy technicians. The financial type the measurement of the economic impact of adult's standardized concentration of chemotherapy medications. The customer types might measure the patients and healthcare providers, including the pharmacy staff of adults, standardized concentration of chemotherapy medications satisfaction in the Kingdom of Saudi Arabia.

\section{Risk Management}

The risk management had several types including budget risks, scope risks, schedule risks, personal risks, technical risks and quality risks. ${ }^{[21,22]}$ The project could be exposed to risks such as personnel, budget, technical and quality risks. The project may be had personal risks for an instant; there is not trained pharmacy staff or nor sufficient pharmacy. Another risk with the budget types, for example, shortage of pharmacy staff or not trained pharmacists and pharmacy technicians. Also, the budget risks might be exposed to the projects, for instance, if there is not enough budget for education and training or update resources. On the other hand, the technical risk may be exposed including there is a computerized system during prescribing. The new project might expose to quality risks related to non-available medications safety measures or shortage of total quality management pharmacists or pharmacy technicians.

\section{Closing of the Project}

The standardized concentration of adults chemotherapeutic at all healthcare hospitals and primary healthcare centers with different governmental and private sectors are highly optional to prevent drug-related morbidity and mortality and avoid additional unnecessary cost on healthcare services in the Kingdom of Saudi Arabia. The project should continue at IV admixture at each pharmacy department with the engrossment of related committees. The Education and training of standardized adult concentration should be showed regularly. Update and parental medications for adult's standardized concentration are required in the future. The annual celebration of all pharmacist and pharmacy technician staff with encouraging them is highly recommended in Saudi Arabia.

\section{ACKNOWLEDGEMENT}

None.

\section{CONFLICT OF INTEREST}

None.

\section{FUNDING}

None.

\section{CONSENT FOR PUBLICATIONS}

Informed consent was obtained from all the participants

\section{ETHICAL APPROVAL}

This research exempted from research and ethical committee or an institutional review board (IRB) approval.

https://www.hhs.gov/ohrp/regulations-andpolicy/decision-charts-2018/index.html

\section{ABBREVIATIONS}

MOH: Ministry of Health; KSA: Kingdom of Saudi Arabia; ASHP: American Society of Health-System Pharmacists; SWOT: Strengths, Weaknesses, Opportunities and Threats; IV: Intravenous; BSC: Balance Scored Cards.

\section{ORCID ID}

Yousef Ahmed Alomi (iD https://orcid. org/0000-0003-1381-628X

\section{REFERENCES}

1. Alomi YA. National medication safety program at ministry of health in Saudi Arabia. J Pharmacovigil. 2015;3(5):e145.

2. Institute for Safe Medication Practices. ISMP List of High-Alert Medications in Acute Care Settings 2018. Available from: https://www.ismp.org/sites/ default/files/attachments/2018-08/highAlert2018Acute-Final.pdf.

3. United States Pharmacopeia. Hazardous DrugsHandling in Healthcare Settings. The United States Pharmacopeial Convention. 2017;1-20.

4. Goldspiel B, Hoffman JM, Griffith NL, et al. ASHP guidelines on preventing medication errors with chemotherapy and biotherapy. Am J Health Syst Pharm. 2015;72(8):e6-35. 
5. American Society of Health-System Pharmacists. Standardized Concentrations: Adult Continuous IV Infusions Version 1.01. 2016. Available from https:// www.ashp.org/-/media/assets/pharmacy-practice/s4s/docs/s4s-iv-adult-continuous-infusionguiding-principles.ashx

6. Traynor K. Medication standardization effort aims to improve patient safety. American Society of Health-Systems Pharmacy. 2016;73(15):1121.

7. Murray KL, Wright D, Laxton B, et al. Implementation of standardized pediatric i.v. medication concentrations. Am J Heal Pharm. 2014;71(17):1500-

8. Lucas AT, Rowe E, Eckel SF. Determining the need for standardized infusions and concentrations at hospitals within North Carolina. Hosp Pharm. 2016;51(3):237-45.

9. Hilmas E, Sowan A, Gaffoor M, et al. Implementation and evaluation of a comprehensive system to deliver pediatric continuous infusion medications with standardized concentrations. Am J Heal Pharm. 2010;67(1):58-69.

10. Bullock J, Jordan D, Gawlinski A, et al. Standardizing IV infusion medication concentrations to reduce variability in medication errors. Crit Care Nurs Clin North Am. 2006;18(4):515-21.

11. Nemec K, Kopelent-Frank H, Greif R. Standardization of infusion solutions to reduce the risk of incompatibility. Am J Heal Pharm. 2008;65(17):1648-54.

12. Westerkamp T. Standardized concentrations for intravenous drip medications. Am J Hosp Pharm. 1988;45(9):1862.

13. Alomi YA. National Intravenous (IV) Therapy Program at $\mathrm{MOH}$ in Saudi Arabia. EC Pharm Sci. 2016;3(2-3):307-11.

14. McDonough R. Writing a business plan for a new pharmacy service. The Dynamics of Pharmaceutical Care: Enriching Patients Health. 2010;23.
15. Harris IM, Baker E, Berry TM, et al. Developing a Business-Practice Model for Pharmacy Services in Ambulatory Settings. Pharmacotherapy. 2008;28(2):7e-34e.

16. Sachdev G. Sustainable business models: Systematic approach toward successful ambulatory care pharmacy practice. Am J Heal Pharm. 2014;71(16):1366-74.

17. PMBOK Guide. A guide to the project management body of knowledge. Sixth Edition. Project Management Institute Inc. 2017.

18. Mitchell A, Sommo P, Mocerine T, et al. A Standardized Approach to Pediatric Parenteral Medication Delivery. Hospital Pharmacy. 2004;39:433-59.

19. Sowan AK, Vaidya VU, Soeken KL, et al. Computerized orders with standardized concentrations decrease dispensing errors of continuous infusion medications for pediatrics. J Pediatr Pharmacol Ther. 2010;15(3):189-202.

20. Kaplan RS, Norton DP. The balanced scorecard: Measures that drive performance. Harvard Business Review. 2005;83(7):172. Cited 2020 Mar 15. Available from: https://hbr.org/1992/01/thebalanced-scorecard-measures-that-drive-performance-2.

21. Ray S. The risk management process in project management. Project Manager. 2017. Cited 2020 Mar 15. Available from: https://www.projectmanager.com/blog/risk-management-process-steps.

22. Kaplan RS, Mikes A. Managing risks: A new framework. Harvard Business Review. 2012:90(6):4860. Cited 2020 Mar 15. Available from: https://hbr org/2012/06/managing-risks-a-new-framework.

23. Benizri $F$, Bonan B, Ferrio $A L$, et al. Stability of antineoplastic agents in use for home-based intravenous chemotherapy. Pharm World Sci. 2009;31(1):1-13.

24. Vigneron J, Astier A, Trittler R, et al. SFPO and ESOP recommendations for the practical stabil- ity of anticancer drugs: An update. Eur J Oncol Pharm. 2014;8(2):3-13.

25. Adams SC, Vyas HM, Anderson RW. Pharmaceutical issues in infusion chemotherapy stability and compatibility. In: Cancer Chemotherapy by Infusion. 1987;100-13

26. Ministry of Health. Ministry of Health Formulary. Health Ministry of Health. 2012.

27. Saudi Food and Drug Authority. List of human medicine and herbal health [Internet]. [cited 2019 Jun 17]. Available from: https://www.sfda.gov.sa/ en/drug/resources/Pages/DrugsUnderRegistrations.aspx

28. Baxter K, Aikman K, Luckhurst R, et.al. British National Formulary 78 (BNF). Royal Phamaceutical Society; 1-1701.

29. Alomi YA, et al. Adults Parenteral Dilution Manual. 2015. Available from: https://www.researchgate. net/publication/281710454_Adults_Parenteral_Dilution_Manual

30. Wolters Kluwer Clinical Drug Information. Inc. (Lexi-Drugs). Wolters Kluwer Clinical Drug Information, Inc.; 2020.

31. Drugs.com. Drugs.com, Prescription Drug Information, Interactions \& Side Effects [Internet] Drugs.com. 2020 [cited 2020 Jun 16]. Available from: https://www.drugs.com/

32. King Abdulaziz Medical City. Unified IV Manual. 2020.

33. Wolters Kluwer Clinical Drug Information. Inc. (ASHF Essentials adults and pediatrics). Wolters Kluwer Clinical Drug Information, Inc.; 2020.

34. Wolters Kluwer Clinical Drug Information. Inc. (Pediatrics \& Neonatal Lexi-Drugs). Wolters Kluwer Clinical Drug Information, Inc.; 2020.

35. Wolters Kluwer Clinical Drug Information. Inc. (Nursing Lexi-Drug). Wolters Kluwer Clinical Drug Information, Inc.; 2020 